\title{
Sonographic Evaluation of the Yolk Sac and its Relationship to the Pregnancy Outcome
}

\author{
RASHA A. EL-SHEIKH ALI, M.Sc.; AHMED M. AWARA, M.D.; EMAD M. MASHALY, M.D. and \\ NAREMAN M. EL HAMAMY, M.D.
}

The Department of Obstetrics and Gynecology, Faculty of Medicine, Tanta University

\begin{abstract}
Background: The yolk sac is the first anatomical structure identified ultrasonographically within the gestational sac and acts as the primary route of exchange between the human embryo and the mother before the placental circulation is established.

Aim of Study: To determine whether yolk sacs with an abnormal sonographic appearance in pregnancies at 5-10 weeks gestation, are associated with adverse pregnancy outcomes or not.

Patients and Methods: This study included one hundred pregnant women who are between 5-10 weeks of gestation at Tanta University Hospitals. They were prospectively evaluated concerning for sonographic characteristics of the yolk sacs and perinatal outcomes.

Results: An abnormal yolk sac was found in 42 pregnancies. In pregnancies with enlarged yolk sacs, a miscarriage occurred in $71.4 \%$ of cases $(5 / 7)$. The pregnancies with a yolk sac diameter $\geq 6 \mathrm{~mm}$ had a significantly higher risk of miscarriage $(p=0.001)$. Miscarriage occurred in $29.4 \%$ of pregnancies with irregular yolk sacs $(5 / 17)$ and $30.8 \%$ of pregnancies with echogenic yolk sacs $(4 / 13)$.

Conclusions: An enlarged yolk sac is strongly associated with a significantly increased risk for miscarriage. The presence of an echogenic or irregular yolk sac appears to be unrelated to adverse perinatal outcome.
\end{abstract}

Key Words: Yolk sac-Pregnancy - A transvaginal ultrasound - Miscarriage - Perinatal outcome.

\section{Introduction}

THE yolk sac is the first anatomical structure identified ultrasonographically within the Gestational sac. It is usually identifiable as a round structure, made up of an anechoic center, and bordered by an echogenic, round, regular and welldefined rim [1].

Correspondence to: Dr. Rasha A. El-Sheikh Ali, The Department of Obstetrics and Gynecology, Faculty of Medicine, Tanta University
Before the placental circulation is established, the yolk sac is considered the primary route of exchange between the human embryo and the mother. It provides nutritional, metabolic, endocrine, immunologic, and hematopoietic functions during organogenesis in embryonic life, and reaches the maximum level of its function between the $4^{\text {th }}$, and $7^{\text {th }}$ week of embryonic development [2].

At the fourth week of embryologic development, the wall of the yolk sac consists of three layers. The outer layer is the ectoderm, which faces the exocoelomic cavity. However, the innermost layer facing the yolk sac cavity is the endodermal epithelium. The mesodermal layer is located between these two layers [3]

The yolk sac can be detected by transvaginal sonography when the mean gestational sac diameter is 5 to $6 \mathrm{~mm}$. The yolk sac should be observed when a gestational sac measures greater than $8 \mathrm{~mm}$. The yolk sac is a sure sign that identifies a real gestational sac [4].

Usually, the inner diameter of a yolk sac measures 3 to $6 \mathrm{~mm}$. The yolk sac size increases progressively from the beginning of the 5 th gestational week to the end of the $10^{\text {th }}$ gestational week. Afterward, the yolk sac dimension falls gradually [5]. The decreased vascularity of the yolk sac at the time of its maximum volume is proposed as the cause of its degeneration and disappearance. That is, the disappearance of arterial signals in the yolk sac circulation and a simultaneous increase in the umbilico-placental blood flow indicates that the transition from the yolk sac to the placenta occurs as an essential source of blood supply to the embryo between $8^{\text {th }}$ and $10^{\text {th }}$ weeks of gestation 
The numbers of yolk sacs present in a gestational sac can succor in decide the amnionicity of the pregnancy. The number of yolk sacs and the number of amniotic sacs equal if the embryos are alive. Thus, there will be two embryos, one chorionic sac, one amniotic sac, and one yolk sac in a monochorionic monoamniotic gestation [7]

It has been hypothesized that abnormal sonographic findings related to the size of the yolk sac can be utilized to anticipate pregnancy outcomes [8]. Some studies suggest that irregular yolk sac shape and echogenic yolk sac can be related to adverse pregnancy outcomes [9]. On the other hand, some authors disagree with this view [10]

Thus, its relationship to gestational outcome required more investigation.

\section{Aim of the work:}

The aim of this study: To determine whether yolk sacs with an abnormal sonographic appearance in pregnancies at 5-10 weeks gestation, are associated with adverse pregnancy outcome or not.

\section{Patients and Methods}

This prospective, observational, analytic cohort study was conducted upon a total number of 100 pregnant women who were between 5-10 weeks of gestation. This study was conducted in the Department of Obstetrics \& Gynecology, University Hospitals of Tanta, 2016-2017. Every case was followed until delivery. All patients were undergoing the standard procedures of the protocol.

Inclusion criteria: Pregnant women who were between 18-30 years old and were between 5-10 weeks of gestation.

Exclusion criteria: Pregnancies with large subchorionic hemorrhage, any uterine anomalies, uterine fibroids, any organic lesion of the uterus, ectopic pregnancy, complete and incomplete hydatiform mole.

The study was approved by the Ethical Committee at the Faculty of Medicine Tanta University. All patients gave oral and written informed consent before the examination.

A full history was taking, full clinical examination and investigations (laboratory: Complete blood picture, $\mathrm{ABO}$ and $\mathrm{Rh}$ groups, random blood sugar, urine analysis and thyroid stimulating hormone, radiological: Transvaginal ultrasound).

Scanning technique: The ultrasound machines used in the ultrasound unit was Mindray DC 30 vaginal probe $6 \mathrm{CV} 1 \mathrm{P}$ multi-frequency $4-9 \mathrm{MHz}$. The gestational age was specified by measurement of the crown-rump length. The yolk sac size was measured by placing the calipers on the inner limits of the yolk sac, shape, echogenicity of rim and center of the sac, numbers of the yolk sac and degenerative changes such as calcification were evaluated.

Yolk sacs that have the following characteristics were classified as normal: Diameter between 3$6 \mathrm{~mm}$, round shape, presence of an echogenic rim and hypo-echoic center and an equal number with embryos.

Yolk sacs that have the following characteristics were classified as abnormal: Diameters smaller than $3 \mathrm{~mm}$ or larger than $6 \mathrm{~mm}$, irregular shape (i.e., oval, with wrinkled margins or indented walls), and an echogenic yolk sac (i.e., the internal structure of a yolk sac has echogenicity rather than being totally anechoic).

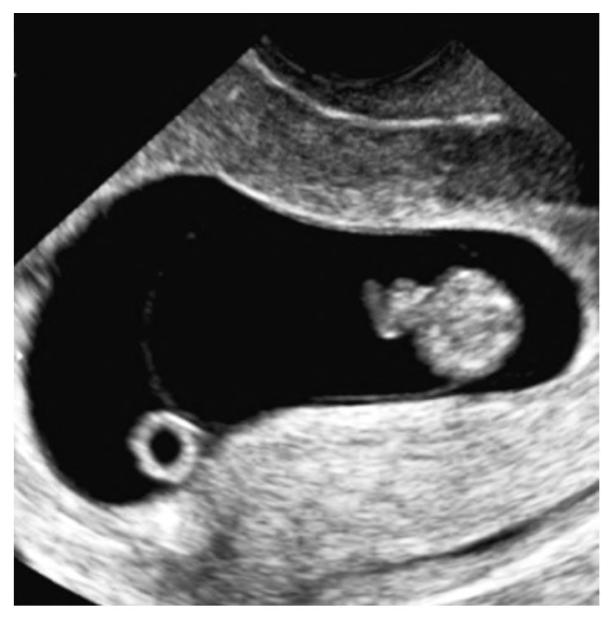

Fig. (1): Normal yolk sac.

All cases were followed until delivery. Fetal scan for any abnormalities was performed at firsttrimester, second-trimester, and third-trimester by Sonographic examinations. Data related to perinatal outcomes were obtained from medical records of the study center and telephone interviews.

Since 8 pregnancies were excluded because of loss to follow-up, the remaining 92 pregnancies were enrolled for final analysis.

An adverse perinatal outcome was defined as either; perinatal morbidity as isolated structural defects, polyhydramnios, oligohydramnios, preeclampsia, gestational diabetes, hyperthyroidism, cholestasis of pregnancy, preterm delivery and respiratory distress syndrome or perinatal mortality as spontaneous miscarriage, intrauterine or neonatal death. 


\section{Statistical analysis:}

Statistical presentation and analysis of the present study was conducted, using the mean, standard deviation and chi-square test by SPSS V. 23.

\section{Results}

The clinical characteristics of the 92 pregnancies reviewed in this study were list in (Table 1).

The mean diameter of the yolk sac increased progressively with increasing gestational age (week) until the end of the 10 th week. This is of $p$-value $0.001 *$.

Normal Yolk Sac was seen in 50 cases of all our 92 cases. All types of abnormalities of Yolk Sac were seen in 42 cases (an absent yolk sac: 5 cases, an enlarged yolk sac: 7 cases, an irregular yolk sac: 17 cases, and an echogenic yolk sac: 13 cases).

Miscarriage have occurred in 5/50 (10\%) of all pregnancies with a normal yolk sac. Miscarriage has occurred in 5/5 (100\%) of all pregnancies with the absent yolk sac. This is of $p$-value $0.001^{*}$.

Miscarriage has occurred in 5/7 (71.4\%) of pregnancies with the abnormally large yolk sac (>6mm in diameter). This is of $p$-value $0.001 *$ (Table 2).

Miscarriage has occurred in 5/17 (29.4\%) of pregnancies with irregular yolk sac. This is of $p$ value 0.063 (Table 3 ).

Miscarriage has occurred in 4/13 (30.8\%) of pregnancies with an echogenic yolk sac. This is of $p$-value 0.067 (Table 4).

Pregnancy complications have occurred in $4.4 \%$ (2/45) of pregnancies with normally yolk sacs, $0 \%$ $(0 / 2)$ of pregnancies with abnormally large yolk sacs, $8.3 \%$ (1/11) of pregnancies with irregular yolk sacs and $11.1 \%(1 / 8)$ of pregnancies with echogenic sacs. This is of $p$-value $0.758,0.605$, 0.437 respectively (Table 5).

Table (1): Clinical characteristics of the reviewed pregnancies.

\begin{tabular}{lccccc}
\hline & Minimum & Maximum & Mean & S.D & Median \\
\hline Age & 18 & 30 & 24.80 & 3.55 & 26 \\
BMI & 22.03 & 38.05 & 28.66 & 3.76 & 28.49 \\
Gravidity & 1 & 5 & 2.32 & 1.17 & 3 \\
Parity & 0 & 3 & 1.18 & 1.00 & 1 \\
\hline
\end{tabular}

Table (2): Correlation of the enlarged yolk sac with Miscarriage

\begin{tabular}{|c|c|c|c|}
\hline & \multicolumn{2}{|c|}{ Abortion } & \multirow{2}{*}{ Total } \\
\hline & Yes & No & \\
\hline \multicolumn{4}{|l|}{ Normal: } \\
\hline $\mathrm{N}$ & 5 & 45 & 50 \\
\hline$\%$ & $10 \%$ & $90 \%$ & $100 \%$ \\
\hline \multicolumn{4}{|l|}{ Enlarged: } \\
\hline $\mathrm{N}$ & 5 & 2 & 7 \\
\hline$\%$ & $71.4 \%$ & $28.6 \%$ & $100 \%$ \\
\hline \multicolumn{4}{|l|}{ Total: } \\
\hline $\mathrm{N}$ & 10 & 47 & 57 \\
\hline$\%$ & $17.5 \%$ & $82.5 \%$ & $100.0 \%$ \\
\hline $\begin{array}{c}\text { Chi-squar } \\
\chi^{2} \\
p \text {-value }\end{array}$ & & $\begin{array}{l}16.024 \\
0.001 *\end{array}$ & \\
\hline
\end{tabular}

Table (3): Correlation of the irregular yolk sac with Miscarriage.

\begin{tabular}{clll}
\hline & \multicolumn{2}{c}{ Abortion } & Total \\
\cline { 2 - 3 } & Yes & No & \\
\hline Normal: & & & \\
$\mathrm{N}$ & 5 & 45 & 50 \\
$\%$ & $10 \%$ & $90 \%$ & $100 \%$ \\
Irregular: & & & \\
$\mathrm{N}$ & 5 & 12 & 7 \\
$\%$ & $29.4 \%$ & $70.6 \%$ & $100 \%$ \\
Total: & & & \\
$\mathrm{N}$ & 10 & 57 & 67 \\
$\%$ & $14.9 \%$ & $85.1 \%$ & $100.0 \%$ \\
Chi-square: & & & \\
$\mathrm{x}^{2}$ & & 3.763 & \\
$p^{\text {- }}$ & & 0.063 & \\
\hline
\end{tabular}

Table (4): Correlation of yolk sac abnormalities with Miscarriage.

\begin{tabular}{|c|c|c|c|}
\hline & \multicolumn{2}{|c|}{ Abortion } & \multirow{2}{*}{ Total } \\
\hline & Yes & No & \\
\hline \multicolumn{4}{|l|}{ Normal: } \\
\hline $\mathrm{N}$ & 5 & 45 & 50 \\
\hline$\%$ & $10 \%$ & $90 \%$ & $100 \%$ \\
\hline \multicolumn{4}{|c|}{ Echogenic: } \\
\hline $\mathrm{N}$ & 4 & 9 & 13 \\
\hline$\%$ & $30.8 \%$ & $69.2 \%$ & $100 \%$ \\
\hline \multicolumn{4}{|l|}{ Total: } \\
\hline $\mathrm{N}$ & 9 & 54 & 63 \\
\hline$\%$ & $14.3 \%$ & $85.7 \%$ & $100.0 \%$ \\
\hline $\begin{array}{l}\text { Chi-squar } \\
\chi^{2} \\
p \text {-value }\end{array}$ & & $\begin{array}{l}3.632 \\
0.067\end{array}$ & \\
\hline
\end{tabular}


Table (5): Correlation of the abnormal yolk sac with pregnancy complications after the first trimester.

\begin{tabular}{lccccccc}
\hline \multirow{2}{*}{ Complications } & \multicolumn{3}{c}{ Yes } & \multicolumn{2}{c}{ No } & \multirow{2}{*}{$\mathrm{X}^{2}$} & $p$-value \\
\cline { 2 - 5 } & No. & $\%$ & No. & $\%$ & & \\
\hline Normal $(\mathrm{n}=45)$ & 2 & 4.4 & 43 & 95.6 & & \\
Enlarged $(\mathrm{n}=2)$ & 0 & 0 & 2 & 100 & 0.102 & 0.758 \\
Irregular $(\mathrm{n}=12)$ & 1 & 8.3 & 11 & 91.7 & 0.273 & 0.605 \\
Echogenic $(\mathrm{n}=9)$ & 1 & 11.1 & 8 & 88.9 & 0.604 & 0.437 \\
\hline
\end{tabular}

\section{Discussion}

The present study was conducted upon a total number of 92 pregnant women who were admitted at Tanta University Hospitals. An absent yolk sac was associated with missed abortion in all cases of this study. In 2016, Ashoush Sh, et al., reported that the majority of their embryos with absent YS were GD1 (Growth disorganized (GD) 1, corresponding with the absent embryo (blighted ovum) [1].Although there is no clear agreement, an enlarged yolk sac can be depicted as a yolk sac with a diameter of 5 or $6 \mathrm{~mm}$. Generally, it has been suggested that an abnormally large yolk sac indicates poor obstetric outcome [11]. A recent study has shown that a yolk sac diameter of greater than $6 \mathrm{~mm}$ is associated with an increased risk of spontaneous abortion [1]. However, a few authors have mentioned the existence of a very large yolk sac (with a diameter of $8.1 \mathrm{~mm}$ ) in normal live pregnancy [12]

In 2014, Tan et al., reported that an enlarged yolk sac was noted in eight pregnancies $(2.6 \%)$. Nearly $40 \%$ of these pregnancies resulted in a firsttrimester miscarriage. These findings indicate that the existence of an enlarged yolk sac (with a diameter of $>5 \mathrm{~mm}$ ) is of evident clinical significance when it is specified before the $7^{\text {th }}$ week of gestation [2].In 2015, Shetty et al., also reported that a yolk sac greater than $5 \mathrm{~mm}$ (large yolk sac) between 67.5 weeks gestation was a good indicator and that it would end in abortions [13] . In 2016, Ashoush et al., a large yolk sac was most commonly detected (in $36.8 \%$ ) with isolated congenital anomalies (representing $63.6 \%$ of all cases with too-large yolk sac) [1]. In 2016, Srivastava et al., also reported that an enlarged yolk sac was responsible for $77.78 \%$ of the abortions [14] . In this study, an enlarged yolk sac has been noted in seven pregnancies $(7.6 \%)$ of all cases. Nearly $71.4 \%$ (5/7) of pregnancies with enlarged yolk resulted in firsttrimester miscarriage when compared with pregnancies that had normal yolk sac diameter, firsttrimester miscarriage occurred in 10\% (5/50) of these pregnancies. These findings indicate that the existence of an enlarged yolk sac (with a diameter of $\geq 6 \mathrm{~mm}$ ) is of evident clinical significance.

Tan et al., reported that an irregular yolk sac was observed in 52 pregnancies $(17.1 \%)$ and approximately $4 \%$ of them ended up with a miscarriage before the 10 th week of gestation. The detection of an irregular yolk sac did not significantly change the miscarriage risk and was found to be unrelated to an adverse perinatal outcome [2]. This also reported by Ashoush et al., [1]. In this study, an irregular yolk sac has been noted in 17 pregnancies $(14.1 \%)$ of all cases. Nearly $29.4 \%$ of these pregnancies resulted in a first-trimester miscarriage. These findings indicate that the existence of an irregular yolk sac did not significantly change the miscarriage risk.

To the best of our knowledge, two studies have reported that an echogenic yolk sac can be associated with early pregnancy loss [15]. On the other hand, Tan et al., reported that an echogenic yolk sac was detected in six pregnancies (1.9\%), which turned out to have normal yolk sacs before the 10 gestational weeks. Moreover, the presence of an echogenic yolk sac was found to be unrelated to an adverse perinatal outcome [2]. In this study, an echogenic yolk sac has been noted in 13 pregnancies $(14.1 \%)$. Nearly $30.8 \%$ of these pregnancies resulted in a first-trimester miscarriage. These findings indicate that the existence of an irregular yolk sac did not significantly change the miscarriage risk. Pregnancy complications have occurred in $4.4 \%(2 / 45)$ of pregnancies with normally yolk sacs, $0 \%(0 / 2)$ of pregnancies with abnormally large yolk sacs, $8.3 \%(1 / 11)$ of pregnancies with irregular yolk sacs and $11.1 \%$ (1/8) of pregnancies with echogenic sacs. An irregular yolk was found to be unrelated to adverse perinatal outcome. The present study prospectively evaluates and offers a longitudinal scan for pregnancies with both normal and abnormal yolk sacs. Although these factors may provide some advantages, there are two factors limiting the power of the findings of the present study. First, this study ignores several factors that may interfere with the course of pregnancy (e.g. smoking, obesity, polycystic ovary syndrome). Second, this study reviews a small number of pregnancies with enlarged, irregular or echogenic yolk sacs.

\section{Conclusion:}

An absent yolk sac has a good indicator for first-trimester miscarriage that can be easily diagnosed by transvaginal sonography from 5-10 weeks gestation. An enlarged yolk sac is strongly associated with a significantly increased risk for miscar- 
riage. Therefore, any pregnancy that is sonographically identified with an enlarged yolk sac should be monitored closely. The presence of irregular or echogenic yolk sac appears to be unrelated to adverse perinatal outcome. Also, as gestational age advances, these abnormalities in the sonographic appearance of a yolk sac are unrelated to adverse perinatal outcome.

\section{References}

1- ASHOUSH S., ABUELGHAR W., TAMARA T. and ALJOBBOURY: Relation between types of yolk sac abnormalities and early embryonic morphology in firsttrimester missed miscarriage. J. Obstet. Gynaecol. Res., Vol. 42, No. 1: 21-8, doi: 10.1111/jog.12837, 2016.

2- TAN S., TANGAL N.G., KANAT-PEKTAS M., et al.: Abnormal sonographic appearances of the yolk sac: Which can be associated with adverse perinatal outcome? Med. Ultrasound, Vol. 16, No. 1, 15-20 Doi: 10.11152/mu, 2014.

3- TAN S., PEKTAS, M.K. and HALIL ARSLAN: Sonographic Evaluation of the Yolk Sac. JUM Vol. 31 No. 1 87-95, 2012.

4- MORIN L. and MICHIEL C.V.: Ultrasound Evaluation of First Trimester Pregnancy Complications, Journal of Obstetrics and Gynaecology Canada, Volume 27, Issue 6, Pages 581-5, 2005.

5- MORADAN S. and FOROUZESHFAR M.: Are Abnormal Yolk Sac Characteristics Important Factors in Abortion Rates? Int. J. Fertil Steril, 6 (2): 127-30, 2012.

6- MURALIDHAR G. KAMALAPUR and PREETAM P., DASAR S.: Sonographic evaluation of yolk sac size and its outcome in first trimester pregnancy. Volume-7 Issue3, ISSN No 2277-8179, IF: 4.758, IC Value: 93-8, 2018.

7- LYONS E.A. and LEVI C.S.: The First-trimester ultrasound, In: Rumack C.M., Wilson S.R., Charboneau J.W. (eds). Diagnostic Ultrasound. $3^{\text {rd }}$ ed.St Louis, MO: CV Mosby Co, 1070-100, 2005.

8- RICHARDSON A., GALLOS I., DOBSON S., et al.: Accuracy of first-trimester ultrasound in diagnosis of intrauterine pregnancy prior to visualization of the yolk sac. Ultrasound Obstet. Gynecol., 10.1002/uog.14725, 2015.

9- SCHMIDT P., HÖRMANSDÖRFER C., BOSSELMANN S., et al.: Is the yolk sac a new marker for chromosomal abnormalities in early pregnancy? Arch. Gynecol. Obstet., 283: 23-6, 2011.

10- TAN S., PEK A., PEKTAS M.K., et al.: Irregular yolk sac shape: Is it really associated with an increased risk of spontaneous abortion? J. Ultrasound Med., 30: 31-6, 2011 .

11- JONES C., PENZKOVER D., POLLARD R., et al.: FirstTrimester Embryology: An Overview in First-Trimester Ultrasound, Springer International Publishing Switzerland J.S. Abramowicz, Doi 10.1007/978-3-319-20203-7. p. 59-76, 2016.

12- CHO F.N., CHEN S.N., TAI M.H., et al.: The quality and size of yolk sac in early pregnancy loss. Australian and New Zealand Journal of Obstet. Gynaecol., 46: p. 4138, 2006.

13- SHETTY A.S., SHETTY H., HEGDE D., et al.: Yolk Sac Abnormalities-Is It a Reliable Indicator of Abortions?-A Prospective Study in the Population Residing in Rural Setup of Mangaluru, Karnataka, India. Journal of Pharmaceutical and Biomedical Sciences, 5 (5): p. 380-4, 2015.

14- SRIVASTAVA G., NAGWANI M., PASRICHA N., et al.: Size of Yolk Sac by Ultrasonography and its Correlation with Pregnancy Outcome. International Journal of Anatomy and Research, 4 (1): p. 2052, 2016.

15- PRASHANTH A., SELVI C., LAVANYA R., et al.: Evaluation of yolk sac diameter and embryonic heart rate as prognostic factors of gestational outcome in early singleton pregnancies. Scholars Journal of Applied Medical Sciences, 3 (2): p. 543-50, 2015. 


\section{تقييم آنواع الكيس المحى بالموجات فوق الصوتية وعلاقته بناتج الحمل في فوجل}

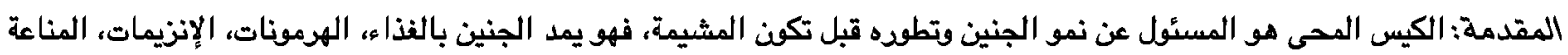

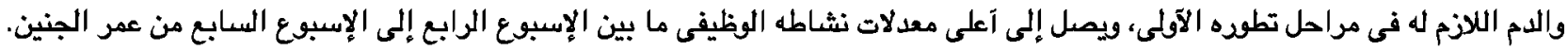
يظهر الكيس المحى عن طريق الكشف بالموجات فوق الصوتية عبر المهبل بشكل دائرى، معتم من الداخل ومضئ من الخارج، محيطه ها بين ب إلى דمم.

الهدف من البحث: معرفة ما إذا كان نتائج الموجات فوق الصوتية عبر المهبل الفير طبيعية المتعلقة بالصجم والشكل والهيكل الداخلى

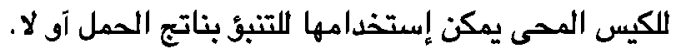

المرضى وطرق البحث: هذه الدراسة دراسة رقابية مقبله تمت فى قسم التوليد وآمراض النساء بمستثفى طنطا الجامعى إبتداء من يناير

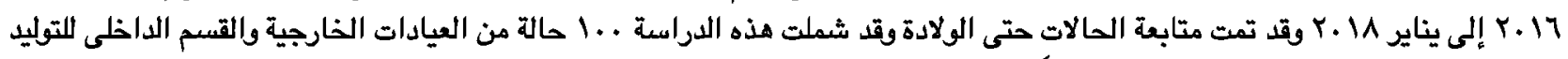

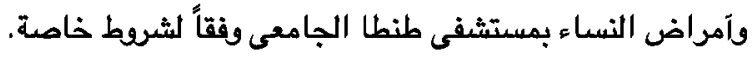

النتائج: بمقارنة النتائج إحصائياً تبين آن السيدات الحوامل التى لا يوجد بحملهن كيس محى ينتهى حملهن بالإجهاض قبل با إسبوع من الحمل.

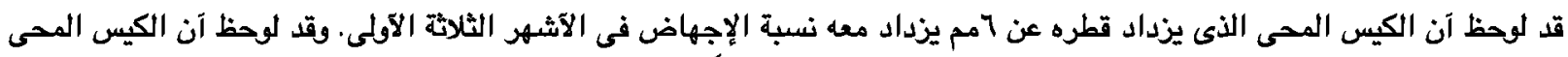

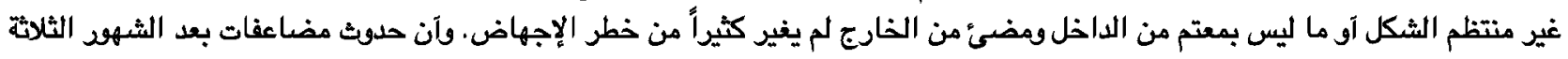
الآولمى ليس له علاقة بالتفير في الكيس المحى التئ. 